\title{
Association of TLR7 and TSHR copy number variation with Graves' disease and Graves' ophthalmopathy in Chinese population in Taiwan
}

\author{
Wen-Ling Liao ${ }^{1,2}$, Lei Wan ${ }^{3,4,5}$, Tzu-Yuan Wang ${ }^{6}$, Ching-Chu Chen ${ }^{6}$, Siu-San Tse ${ }^{7}$, Chieh-Hsiang Lü8,9,10 \\ and Fuu-Jen Tsai ${ }^{3,4,5,11^{*}}$
}

\begin{abstract}
Background: Graves' disease (GD) and Graves' ophthalmopathy (GO) are autoimmune disorders, which might be influenced by genetic factors. Copy number variation (CNV) is an important source of genomic diversity in humans, and influences disease susceptibility. This study investigated the association between CNV in the TSHR and TLR7 genes and the development of GD and GO in a Chinese population in Taiwan.

Methods: For this case-control study, sample from 196 healthy controls and 484 GD patients, including 203 patients with GO were studied. CNV was detected by real-time polymerase chain reaction (PCR) using TaqMan ${ }^{\mathrm{TM}}$ probes and the relative copy number (CN) was estimated by using the comparative $C_{t}$ method.

Results: The differences in the distribution of TSHR CNV in healthy controls and GD patients were statistically significant ( $p$ value $=0.01$ ). However, the difference in the distribution of TSHR CNV in the control group and the GO group was not statistically significant ( $p$ value $=0.06$ ). For $T L R 7 C N V$, the results were not significantly different when we compared the distribution in healthy controls and GD patients and in healthy controls and GO patients ( $p$ values for Fisher's exact test were 0.13 and 0.09, respectively). However, a lower than normal CNV for TLR7 (CNV $<2$ for female and CNV $<1$ for male) was found to have a protective effect against the development of GD (odds ratio $(\mathrm{OR})=0.24 ; 95 \%$ confidence interval $(\mathrm{Cl}), 0.07-0.75)$ after adjusting for age and gender.
\end{abstract}

Conclusions: These results suggested that TSHR and TLR7 CNV might be associated with susceptibility to GD.

Keywords: Graves' disease, Graves' ophthalmopathy, Copy number variation, TSHR, TLR7, Taiwan

\section{Background}

Copy number variation $(\mathrm{CNV})$ refers to is a genomic variation in the number of copies of a $>1$-kb DNA segment compared to a reference genome. Gene copy number (CN) differences due to deletions, duplications, and insertions might contribute to variations in gene expression, phenotypic variation, and gene dosage. Therefore, CNVs might play an important role in not only evolution and adaptation to different environments, but also in susceptibility to and severity of disease [1,2]. Recently CNV has been used as a genetic marker for inter-individual variation

\footnotetext{
*Correspondence: d0704@www.cmuh.org.tw

${ }^{3}$ Department of Medical Genetics and Medical Research, China Medical University Hospital, No.2 Yuh-Der Road, 404 Taichung City, Taiwan

${ }^{4}$ School of Chinese Medicine, China Medical University, No.91 Hsueh-Shih Road, 404 Taichung City, Taiwan

Full list of author information is available at the end of the article
}

to investigate human genomic diversity. For example, the associations between $\mathrm{CNV}$ and diseases such as autism [3,4], schizophrenia [5], cancer [6-8], and autoimmune disorders [9-13] have been discussed in numerous studies.

Graves' disease (GD) is an organ-specific autoimmune disease caused by autoantibodies against thyroid-stimulating hormone receptors (TSHRs); these antibodies constitutively stimulate the production of thyroid hormones. TSHR is a 7-transmembrane domain $\mathrm{G}$ protein-coupled receptor in the thyroid gland that binds thyroid-stimulating hormone (TSH). Therefore, the TSHR gene on chromosome $14 \mathrm{q}$ is a candidate disease-susceptibility gene for GD and the association between TSHR gene polymorphism and GD has been investigated [14-16].

Graves' ophthalmopathy (GO) is the most common extrathyroidal manifestation of GD and affects $25-50 \%$ 
of patients with GD [17-20]. GO is an autoimmune inflammatory disorder that affects the extraocular muscles and the fatty and connective tissues in the orbit of the eye. Studies have shown that genes related to the immune system, such as human leucocyte antigen (HLA), cytotoxic T cell antigen-4 genes (CTLA), CD103 and Interleukin13 (IL-13) are involved in the pathogenesis of GD or GO $[17,21,22]$. Recently, toll-like receptors (TLRs), which play important roles in eliciting human innate/adaptive immune responses and developing chronic inflammation [23], have become a new focus of basic immunological investigation and might be associated with autoimmune thyroiditis [24]. TLR7 gene, which is located on the X chromosome, is expressed in human plasmacytoid dendritic cells (pDCs) and specifically recognizes singlestranded RNA derived from viruses or immune complexes associated with self-RNA. This results in the activation of the pDCs and induces the secretion of large amounts of interferon alpha (IFN- $\alpha$ ), which in turn has a pivotal role in the pathogenesis of GD/GO. Therefore, TLR7 gene could be a potential immune-related disease-susceptibility gene for GD/GO. In this study, we examined the association of the CNV in TSHR and TLR-7 with susceptibility to GD and GO in a population of Chinese people in Taiwan.

\section{Methods}

\section{Study population}

The participants in this study were 196 healthy controls and 484 GD patients which including 203 of them with ophthalmopathy (GO) recruited from China Medical University Hospital in Taiwan. All GD patients were examined by experienced endocrinologist and identified using following criteria: having hyperthyroidism, having diffused goiter and presence at least one of following observations: positive results for thyroid-stimulating hormone (TSH) receptor receptor antibody test, diffusely increased ${ }^{131}$ I (iodine-131) uptake in the thyroid gland, and exophthalmos. GD patients were categorized according the NOSPECS system recommended by the American Thyroid Association [25]. The GD patients had proptosis with or without more severe form (class 3-6) was defined as GO (yes/no). The degree of proptosis was measured using an exophthalmometer and was defined as the apex of the cornea and the lateral orbital rim is more than $18 \mathrm{~mm}$ in either eye or a 2-mm difference in the degree of protrusion between the 2 eyes. The information regarding age, sex, history of tobacco use, thyroid gland pathology and affected anatomic sites were obtained from the questionnaire and blood samples were collected by venipuncture for genomic DNA isolation. Informed consent was obtained from each participant prior to inclusion in this study and the human ethics committee of China Medical University Hospital gave its approval for the study.

\section{DNA preparation and TaqMan real-time polymerase chain reaction (rt-PCR)}

The genomic DNA was extracted from peripheral blood leukocytes of participants using the Genomic DNA kit (Qiagen) according to the manufacturer's instructions. It is important to verify the quality of each genomic DNA in order to get accurate CN. Therefore, all genomic DNA were electrophoresed on an agaroes gel and integrity scored from 1 to 4 (most degraded). Samples with scores of 3 and 4 were discarded from analysis. Also, in order to minimized DNA degradation, the template DNA were freshly diluted from $200 \mu \mathrm{g} / \mathrm{ml}$ stock and used within 2 weeks.

\section{Measurement of CN}

The relative $\mathrm{CN}$ of the TSHR and TLR7 gene in each individual was estimated using TaqMan real-time quantitative polymerase chain reaction (rt-PCR) method that is suited to large-scale genotyping. rt-PCR was performed using the ABI 7900 HT sequence detection system. Amplification reactions $(14 \mu \mathrm{l})$ were carried out in duplicate with of template DNA (10 ng), reference DNA (RNase P H1 RNA gene (10 ng)), TaqMan Universal Master Mix buffer (Applied Biosystems, Foster City, CA), 300 nM of each primer and $200 \mathrm{nM}$ of each fluorogenic probe (probe with FAMTM dye and $\mathrm{VIC}^{\oplus}$ dye). Thermal cycling was initiated with a first denaturation step of $10 \mathrm{~min}$ at $95^{\circ} \mathrm{C}$, and followed by 40 cycles of $15 \mathrm{sec}$ at $95^{\circ} \mathrm{C}$ and of $1 \mathrm{~min}$ at $60^{\circ} \mathrm{C}$. The relative gene $\mathrm{CN}$ for each individual was estimated using the comparative $\mathrm{Ct}$ method (2- $\Delta \Delta \mathrm{Ct}$ method) [26]. Briefly, this method calculates the difference in cycle thresholds $(\triangle \mathrm{Ct})$ (the number of PCR cycles required to produce a set of fixed thresholds) between the gene of interest and a reference gene (ribonuclease P, (RNase P). Subsequent calculations normalize the $\Delta \mathrm{Ct}$ of each sample to a calibrator that is assigned a relative expression value of $1.00(\Delta \mathrm{Ct})$. Assuming that the amount of PCR product doubles with each successive PCR cycle, calculating the $2-\Delta \Delta \mathrm{Ct}$ value will provide the relative amount of DNA initially available for amplification in each quantitative PCR run. Therefore, the $2-\Delta \Delta C t$ method reveals differences in the relative gene copy numbers between the samples tested [27]. Here, RNase P which known to exist in two copies in a diploid genome is recommended as the standard reference assay for copy number quantitation experiments. This assay detects the RNase P RNA component H1 (H1RNA) gene (RPPH1) on chromosome 14, cytoband 14q11.2.

The PCR products were quantified in triplicate, and the standard deviation (SD) and coefficient of variation (CV) were calculated based on 3 runs. To control for reaction quality, each reaction plate also included a calibrator, a positive control, and a no-template control (NTC). Data from a plate were included if the calibrator $\mathrm{CV}$ was less than 5\%, the positive control CV and sample CVs were all 
less than $10 \%$, and the NTC was negative. To include across-plate data, the CVs of the positive control had to be similar and the NTC had to be negative.

\section{Data analyses}

Significance of the differences between the distributions of TSHR and TLR7 CNV in groups (healthy controls, GD and GO) was estimated by Chi square test or Fisher exact test. Odds ratios (OR) and 95\% confidence intervals (CI) were estimated by logistic regression models. Age and gender were adjusted in multivariate models. Because the TLR7 gene located on chromosome X, the interaction between gender and CNV of the TLR7 gene was investigated. If the interaction term was not significant, males and females would be combined to further analyses. To estimate OR, the reference category was normal $\mathrm{CNV}$ which are $\mathrm{CNV}=2$ for $T S H R$ gene, $\mathrm{CNV}=2$ for TLR7 gene in females and CNV $=1$ for TLR7 gene in males. Based on the reference category, the risk of GD/ GO associated with the absolute TSHR/TLR7 CNV was estimated by comparing cases and controls groups by $\mathrm{CNV}$ less than normal $\mathrm{CNV}$ and $\mathrm{CNV}$ more than normal CNV.

\section{Results}

In present study, the TSHR and TLR7 genes showed variation in $\mathrm{CN}$ in a Chinese population in Taiwan. Specifically, $14.6 \%$ and $3.5 \%$ of this population had abnormal CNV for TSHR and TLR7, respectively.

\section{The distribution of TSHR copy number variation}

The distribution of TSHR CNV in GD or GO patients is summarized in Table 1 . There was association between TSHR CNV and GD ( $p$ value for Fisher's exact test was 0.01 ). However, the distributions of TSHR CNV in the GO patients and healthy controls were not significantly different ( $p$ value for Fisher's exact test was 0.06). In univariate analyses, a harmful effect of abnormal TSHR $\mathrm{CNV}(\mathrm{CNV}<2)$ on the development of GD and GO were observed $(\mathrm{OR}=2.63 ; 95 \% \mathrm{CI}=1.31-5.25$ and $\mathrm{OR}=2.35$;
95\% $\mathrm{CI}=1.09-5.09$ for comparing healthy control with GD and GO, respectively). After adjusting for age and gender, the results remain significant.

\section{The distribution of TLR7 copy number variation}

The distribution of TLR7 CNV of healthy control subjects and GD patients is shown in Table 2. In healthy control subjects, $94.9 \%$ of healthy control and $97.1 \%$ of GD patients had normal TLR7 CNV. The association between healthy control and GD or GO were not observed ( $p$ values for Fisher's exact test were 0.13 and 0.09, respectively). When we adjusted age and gender in the multivariate logistic regression model, a protective effect of lower than normal CNV for TLR7 $(\mathrm{CNV}<2$ for female and $\mathrm{CNV}<1$ for male), on development of GD was observed $(\mathrm{OR}=0.24 ; 95 \% \mathrm{CI}=0.07-0.75)$. All of GD subjects with $\mathrm{CNV}$ less than normal $\mathrm{CNV}$ were females $(n=6)$. The interaction term between gender and $\mathrm{CNV}$ of the TLR7 gene was investigated and the result was not significant $(p$ value $>0.05)$.

\section{Discussion}

In the present study, variation in the CNs of TSHR and TLR7 gene was observed in the Chinese population in Taiwan, and the effects of this CNV on GD and GO were investigated. To the best of our knowledge, this is the first study to show that CNV in TSHR and TLR7 is associated with GD/GO in the Chinese population in Taiwan. Previous studies on the effects of single nucleotide polymorphisms of the TSHR gene on GD have yielded inconsistent results $[14,16,28]$. Small study sample size and studying difference population for genetic diversity may be the reasons for these non-significant or inconsistent finding. But, a statistically significant association between CNV of the TSHR gene and GD/GO was identified in present study. Genetic variation within the $T S H R$ region may influence TSHR structure, expression and/or post-translational processing, which in turn could initiate or exacerbate the autoimmune response against the TSHR in GD [29].

Table 1 The distribution of TSHR copy number variation in healthy control and patients with Graves' disease and Graves' ophthalmology

\begin{tabular}{|c|c|c|c|c|c|c|c|}
\hline \multirow[b]{2}{*}{ CNV } & \multirow{2}{*}{$\frac{\text { Healthy control }(\mathrm{N}=196)}{\mathrm{N}(\%)}$} & \multirow{2}{*}{$\frac{\mathrm{GD}(\mathrm{N}=481)}{\mathrm{N}(\%)}$} & \multirow{2}{*}{$\frac{\mathrm{GO}(\mathrm{N}=203)}{\mathrm{N}(\%)}$} & \multicolumn{2}{|c|}{ GD versus Healthy control } & \multicolumn{2}{|c|}{ GO versus Healthy control } \\
\hline & & & & OR $(95 \% \mathrm{Cl})^{\mathrm{b}}$ & OR $(95 \% \mathrm{Cl})^{c}$ & OR $(95 \% \mathrm{Cl})^{b}$ & OR $(95 \% \mathrm{Cl})^{c}$ \\
\hline$<2$ & $10(5.1)$ & $59(12.3)$ & $23(11.3)$ & $2.63(1.31-5.25)^{*}$ & $2.61(1.29-5.28)^{*}$ & $2.35(1.09-5.09)^{*}$ & $2.54(1.15-5.61)^{*}$ \\
\hline 2 & $178(90.8)$ & $400(83.2)$ & $174(85.7)$ & 1 & 1 & 1 & 1 \\
\hline$>2$ & $8(4.1)$ & $22(4.6)$ & $6(3.0)$ & $1.22(0.54-2.80)$ & $1.34(0.55-3.27)$ & $0.77(0.26-2.26)$ & $0.98(0.32-3.01)$ \\
\hline$P$ value $e^{a}$ & & $0.01 *$ & 0.06 & & & & \\
\hline
\end{tabular}

$\mathrm{GD}$, Graves' disease. GO, Graves' ophthalmology. CNV, copy number variance. $\mathrm{N}=$ number. OR, odds ratio. $\mathrm{Cl}$, confidence interval.

${ }^{a} P$ value was calculated by Fisher's exact test. Statistically significant results are indicated by asterisk $(*)$.

bUnivariate analyses. Statistically significant results are indicated by asterisk $(*)$.

${ }^{\mathrm{C}}$ Mutivariates analyses, adjusted for age and gender, interaction term (gender*TSHR) was not significant. Statistically significant results are indicated by asterisk ${ }^{*}$ ). 
Table 2 The distribution of TLR7 copy number variation in healthy control and patients with Graves' disease and Graves' ophthalmology

\begin{tabular}{|c|c|c|c|c|c|c|c|}
\hline \multirow[b]{2}{*}{ CNV } & \multirow{2}{*}{$\frac{\text { Healthy control }(\mathrm{N}=196)}{\mathrm{N}(\%)}$} & \multirow{2}{*}{$\frac{G D(N=484)}{N(\%)}$} & \multirow{2}{*}{$\frac{\mathrm{GO}(\mathrm{N}=203)}{\mathrm{N}(\%)}$} & \multicolumn{2}{|c|}{ GD versus Healthy control } & \multicolumn{2}{|c|}{ GO versus Healthy control } \\
\hline & & & & OR $(95 \% \mathrm{Cl})^{c}$ & OR $(95 \% \mathrm{Cl})^{d}$ & OR $(95 \% \mathrm{Cl})^{c}$ & OR $(95 \% \mathrm{CI})^{\mathrm{d}}$ \\
\hline CNV $<$ normal CNV & $7(3.6)$ & $6(1.2)$ & $1(0.5)$ & $0.34(0.11-1.02)$ & $0.24(0.07-0.75)^{*}$ & $0.13(0.02-1.09)$ & $0.13(0.02-1.05)$ \\
\hline Normal CNV ${ }^{a}$ & $186(94.9)$ & $470(97.1)$ & $200(98.5)$ & 1 & 1 & 1 & 1 \\
\hline CNV > normal CNV & $3(1.5)$ & $8(1.7)$ & $2(1.0)$ & $1.06(0.28-4.02)$ & $1.32(0.33-5.26)$ & $0.62(0.10-3.75)$ & $0.67(0.11-4.15)$ \\
\hline$P$ value ${ }^{b}$ & & 0.13 & 0.09 & & & & \\
\hline
\end{tabular}

GD, Graves' disease. GO, Graves' ophthalmology. CNV, copy number variation. $\mathrm{N}$ = number. OR, odds ratio. $\mathrm{Cl}$, confidence interval. \#, number.

${ }^{\mathrm{a}} \mathrm{CNV}=1$ for male or $\mathrm{CNV}=2$ for female.

${ }^{\mathrm{b}} P$ value was calculated by Fisher's exact test.

'Univariate analyses. Statistically significant results are indicated by asterisk $\left(^{*}\right)$.

${ }^{\mathrm{d}}$ Mutivariates analyses, adjusted for age and gender, interaction term (gender*TLR7) was not significant. Statistically significant results are indicated by asterisk ${ }^{*}$ ).

The TLR7 gene belongs to a family of pattern-recognition receptors that recognize nuclear material from apoptotic debris. Researchers have demonstrated that TLR7 plays an important role in producing IFN- $\alpha$, which is a critical player in the innate and adaptive immune system [30,31]. Therefore, it is possible that CNV in TLR7 gene could modulate the autoimmune response to nuclear material [12]. Our results showed that TLR7 CNV is associated with genetic susceptibility to GD, with a wide confidence interval. The issue of limited study power due to the small effect size and limited sample size should be noted. Moreover, a link between TLR7 gene dosage and increased autoimmunity has been identified in a mouse model of systemic lupus erythematosus (SLE) [32,33]; however, the effects of varying TLR7 CN on SLE were inconsistent $[10,12,33]$. In the present study, a protective effect of lower than normal TLR7 CNV (CNV=1 for female) and a harmful effect of higher than normal CNV (result was not significant) on the development of GD was observed. However, a dosage effect of TLR7 on GD/GO was not observed (data not shown). The relationship betweeen TLR7 CNV, TLR7 expression, and IFN- $\alpha$ activation will need to be investigated in future studies.

In our study, the effects of TLR7 CNV on GD and GO were greater when the analyses were limited to female subjects. This gender-related difference in TLR7 function has been observed previously. For example, Berghofer et al. (2006) showed that female SLE patients produce significantly more IFN- $\alpha$ after TLR7 stimulation than male SLE patients. Epidemiological studies also indicate that GD predominantly affects women [34]. Many studies have confirmed that elevated levels of IFN- $\alpha$ play a key role in the development of clinical and experimental GD [35]. Therefore, TLR7 CNV may contribute to the pathogenesis of GD in female patients through a genderdependent immune response. However, the effect of TLR7 CNV in male subjects is unclear owing to the small number of male subjects in this study. Therefore, a larger sample size, especially of the male population will be needed in future studies to confirm the importance of TLR7 CNV as a genetic marker of GD.

\section{Conclusions}

In conclusion, this study suggests that CNV in TSHR and TLR7 is associated with the development of GD. TSHR and TLR7 CNV might therefore be potential diagnostic tests or therapeutic targets for GD.

\section{Competing interests}

The authors declare that they have no competing interests.

\section{Authors' contributions}

WLL performed the statistical analysis and interpretation of data and drafted the manuscript. LW participated in the design of the study and carried out the molecular genetic studies. TYW and CCC participated in acquisition of data. FJT and CHL conceived of the study and participated in its design. All authors read and approved the final manuscript.

\section{Acknowledgements}

We thank Hsin-Hui Chen for the technical assistance in preparation of DNA and analyzing the variations. This study was supported by research grants DMR-101-118 and DMR-102-045 from China Medical University Hospital, Taichung, Taiwan and 98-2320-B-039-008-MY3 from National Science Council, Taipei, Taiwan.

\section{Author details}

${ }^{1}$ Center for Personalized Medicine, China Medical University Hospital, No.2 Yuh-Der Road, 404 Taichung City, Taiwan. ${ }^{2}$ Graduate Institute of Integrated Medicine, China Medical University, No.91 Hsueh-Shih Road, 404 Taichung City, Taiwan. ${ }^{3}$ Department of Medical Genetics and Medical Research, China Medical University Hospital, No.2 Yuh-Der Road, 404 Taichung City, Taiwan. ${ }^{4}$ School of Chinese Medicine, China Medical University, No.91 Hsueh-Shih Road, 404 Taichung City, Taiwan. ${ }^{5}$ Department of Biotechnology, Asia University, No.500 Lioufeng Rd., 413 Taichung City, Taiwan. ${ }^{6}$ Division of Endocrinology and Metabolism, Department of Medicine, China Medical University Hospital, No.2 Yuh-Der Road, 404 Taichung City, Taiwan.

${ }^{7}$ Department of Surgery, Division of Urology, Tung's Taichung Metroharbor hospital, No.699, Sec.1, Chungchi Rd., 435 Taichung City, Taiwan. ${ }^{8}$ Division of Endocrinology and Metabolism of Internal Medicine, Ditmanson Medical Foundation Chia-Yi Christian Hospital, No. 539, 60002 Jhongsiao Rd., Chia-Yi City, Taiwan. ${ }^{9}$ Department of Business Administration, National Chung Cheng University, No.168, Sec. 1, University Rd., Min-Hsiung Township, Chia-yi County 621, Taiwan. ${ }^{10}$ TaTung Institute of Commerce and Technology, 253 Mi-Tuo Road, Chiayi City, Taiwan. ${ }^{11}$ Department of Pediatrics, China Medical University Hospital, No.2 Yuh-Der Road, 404 Taichung City, Taiwan. 


\section{References}

1. Lin CH, Lin YC, Wu JY, Pan WH, Chen YT, Fann CS: A genome-wide survey of copy number variations in Han Chinese residing in Taiwan. Genomics 2009, 94(4):241-246.

2. Redon R, Ishikawa S, Fitch KR, Feuk L, Perry GH, Andrews TD, Fiegler H, Shapero MH, Carson AR, Chen W, et al: Global variation in copy number in the human genome. Nature 2006, 444(7118):444-454.

3. Glessner JT, Wang K, Cai G, Korvatska O, Kim CE, Wood S, Zhang H, Estes A Brune CW, Bradfield JP, et al: Autism genome-wide copy number variation reveals ubiquitin and neuronal genes. Nature 2009, 459(7246):569-573.

4. Sebat J, Lakshmi B, Malhotra D, Troge J, Lese-Martin C, Walsh T, Yamrom B, Yoon S, Krasnitz A, Kendall J, et al: Strong association of de novo copy number mutations with autism. Science 2007, 316(5823):445-449.

5. Walsh T, McClellan JM, McCarthy SE, Addington AM, Pierce SB, Cooper GM, Nord AS, Kusenda M, Malhotra D, Bhandari A, et al: Rare structural variants disrupt multiple genes in neurodevelopmental pathways in schizophrenia. Science 2008, 320(5875):539-543.

6. Diskin SJ, Hou C, Glessner JT, Attiyeh EF, Laudenslager M, Bosse K, Cole K, Mosse YP, Wood A, Lynch JE, et al: Copy number variation at 1q21.1 associated with neuroblastoma. Nature 2009, 459(7249):987-991.

7. Liu W, Sun J, Li G, Zhu Y, Zhang S, Kim ST, Wiklund F, Wiley K, Isaacs SD, Stattin $P$, et al: Association of a germ-line copy number variation at 2p24.3 and risk for aggressive prostate cancer. Cancer Res 2009, 69(6):2176-2179.

8. Shlien A, Malkin D: Copy number variations and cancer susceptibility. Curr Opin Oncol 2010, 22(1):55-63

9. Fanciulli M, Norsworthy PJ, Petretto E, Dong R, Harper L, Kamesh L, Heward JM, Gough SC, de Smith A, Blakemore Al, et al: FCGR3B copy number variation is associated with susceptibility to systemic, but not organ-specific, autoimmunity. Nat Genet 2007, 39(6):721-723.

10. Kelley J, Johnson MR, Alarcon GS, Kimberly RP, Edberg JC: Variation in the relative copy number of the TLR7 gene in patients with systemic lupus erythematosus and healthy control subjects. Arthritis Rheum 2007, 56(10):3375-3378.

11. Mamtani M, Anaya JM, He W, Ahuja SK: Association of copy number variation in the FCGR3B gene with risk of autoimmune diseases. Genes Immun 2010, 11(2):155-160.

12. Ptacek T, Li X, Kelley JM, Edberg JC: Copy number variants in genetic susceptibility and severity of systemic lupus erythematosus. Cytogenet Genome Res 2008, 123(1-4):142-147.

13. Willcocks LC, Lyons PA, Clatworthy MR, Robinson JI, Yang W, Newland SA, Plagnol V, McGovern NN, Condliffe AM, Chilvers ER, et al: Copy number of FCGR3B, which is associated with systemic lupus erythematosus, correlates with protein expression and immune complex uptake. J Exp Med 2008, 205(7):1573-1582.

14. Brand OJ, Barrett JC, Simmonds MJ, Newby PR, McCabe CJ, Bruce CK, Kysela B, Carr-Smith JD, Brix T, Hunt PJ, et al: Association of the thyroid stimulating hormone receptor gene (TSHR) with Graves' disease. Hum Mol Genet 2009, 18(9):1704-1713.

15. Brand OJ, Gough SC: Genetics of thyroid autoimmunity and the role of the TSHR. Mol Cell Endocrinol 2010, 322(1-2):135-143.

16. Yin $X$, Latif $R$, Bahn $R$, Tomer $Y$, Davies TF: Influence of the TSH receptor gene on susceptibility to Graves' disease and Graves' ophthalmopathy. Thyroid 2008, 18(11):1201-1206

17. Gianoukakis AG, Khadavi N, Smith TJ: Cytokines, Graves' disease, and thyroid-associated ophthalmopathy. Thyroid 2008, 18(9):953-958.

18. Khoo TK, Bahn RS: Pathogenesis of Graves' ophthalmopathy: the role of autoantibodies. Thyroid 2007, 17(10):1013-1018.

19. Kuriyan AE, Phipps RP, Feldon SE: The eye and thyroid disease. Curr Opin Ophthalmol 2008, 19(6):499-506.

20. Perros P, Neoh C, Dickinson J: Thyroid eye disease. BMJ 2009, 338:b560.

21. Anvari M, Khalilzadeh O, Esteghamati A, Esfahani SA, Rashidi A, Etemadi A Mahmoudi M, Amirzargar AA: Genetic susceptibility to Graves' ophthalmopathy: the role of polymorphisms in proinflammatory cytokine genes. Eye (Lond) 2010, 24(6):1058-1063.

22. Ban $Y$, Tomer $Y$ : Susceptibility genes in thyroid autoimmunity. Clin Dev Immunol 2005, 12(1):47-58.

23. Drexler SK, Foxwell BM: The role of toll-like receptors in chronic inflammation. Int J Biochem Cell Biol 2010, 42(4):506-518.

24. Caturegli P, Kimura H, Rocchi R, Rose NR: Autoimmune thyroid diseases. Curr Opin Rheumatol 2007, 19(1):44-48.
25. Werner SC: Modification of the classification of the eye changes of Graves' disease: recommendations of the Ad Hoc Committee of the American Thyroid Association. J Clin Endocrinol Metab 1977, 44(1):203-204.

26. Mayo P, Hartshorne T, Li K, McMunn-Gibson C, Spencer K, Schnetz-Boutaud N: CNV analysis using TaqMan copy number assays. Curr Protoc Hum Genet 2010, Chapter 2(Unit2):13

27. Livak KJ, Schmittgen TD: Analysis of relative gene expression data using real-time quantitative PCR and the 2(-Delta Delta $C(T)$ ) method. Methods 2001, 25(4):402-408.

28. Gu LQ, Zhu W, Zhao SX, Zhao L, Zhang MJ, Cui B, Song HD, Ning G, Zhao YJ: Clinical associations of the genetic variants of CTLA-4, Tg, TSHR, PTPN22, PTPN12 and FCRL3 in patients with Graves' disease. Clin Endocrinol (Oxf) 2010, 72(2):248-255.

29. Ploski R, Brand OJ, Jurecka-Lubieniecka B, Franaszczyk M, Kula D, Krajewski P, Karamat MA, Simmonds MJ, Franklyn JA, Gough SC, et al: Thyroid stimulating hormone receptor (TSHR) intron 1 variants are major risk factors for Graves' disease in three European Caucasian cohorts. PLoS One 2010, 5(11):e15512.

30. Berghofer B, Haley G, Frommer T, Bein G, Hackstein H: Natural and synthetic TLR7 ligands inhibit CpG-A- and CpG-C-oligodeoxynucleotideinduced IFN-alpha production. J Immunol 2007, 178(7):4072-4079.

31. Guiducci C, Coffman RL, Barrat FJ: Signalling pathways leading to IFNalpha production in human plasmacytoid dendritic cell and the possible use of agonists or antagonists of TLR7 and TLR9 in clinical indications. J Intern Med 2009, 265(1):43-57.

32. Pisitkun P, Deane JA, Difilippantonio MJ, Tarasenko T, Satterthwaite AB, Bolland S: Autoreactive B cell responses to RNA-related antigens due to TLR7 gene duplication. Science 2006, 312(5780):1669-1672.

33. Garcia-Ortiz H, Velazquez-Cruz R, Espinosa-Rosales F, Jimenez-Morales S, Baca V, Orozco L: Association of TLR7 copy number variation with susceptibility to childhood-onset systemic lupus erythematosus in Mexican population. Ann Rheum Dis 2010, 69(10):1861-1865.

34. Manji N, Carr-Smith JD, Boelaert K, Allahabadia A, Armitage M, Chatterjee VK, Lazarus JH, Pearce SH, Vaidya B, Gough SC, et al: Influences of age, gender, smoking, and family history on autoimmune thyroid disease phenotype. J Clin Endocrinol Metab 2006, 91(12):4873-4880.

35. Kuang $M$, Wang $S$, Wu M, Ning G, Yao Z, Li L: Expression of IFNalphainducible genes and modulation of HLA-DR and thyroid stimulating hormone receptors in Graves' disease. Mol Cell Endocrinol 2010, 319(1-2):23-29.

doi:10.1186/1471-2415-14-15

Cite this article as: Liao et al:: Association of TLR7 and TSHR copy number variation with Graves' disease and Graves' ophthalmopathy in Chinese population in Taiwan. BMC Ophthalmology 2014 14:15.

\section{Submit your next manuscript to BioMed Central and take full advantage of:}

- Convenient online submission

- Thorough peer review

- No space constraints or color figure charges

- Immediate publication on acceptance

- Inclusion in PubMed, CAS, Scopus and Google Scholar

- Research which is freely available for redistribution 